ORIGINAL ARTICLE

\title{
The effects of ankle kinesiotaping on postural control in healthy taekwondo athletes
}

\author{
Yasemin Bayraktar $^{1 \mathrm{ABCDE}}$, Nurtekin Erkmen ${ }^{1 \mathrm{ACE}}$, Yağmur Kocaoğlu ${ }^{1 \mathrm{CBD}}$, Bayram Sönmez Ünüvar ${ }^{2 \mathrm{ABD}}$ \\ ${ }^{1}$ Selcuk University, Konya, Turkey \\ ${ }^{2}$ KTO Karatay University, Vocational School of Health Services, Department of Physiotherapy, Konya, Turkey
}

Authors' Contribution: A - Study design; B - Data collection; C - Statistical analysis; D - Manuscript Preparation; E - Funds Collection.

\begin{abstract}
Background

and Study Aim

Although Kinesiotape is widely used by athletes, information about its effect is unclear. Its effect on postural control might directly affect an athlete's performance. In this study, it is aimed to find out whether ankle Kinesiotaping in taekwondo athletes affects postural control.

Material and Twenty-four healthy university students - taekwondo athletes (12 females, 12 males) were included Methods in the study voluntarily (Age $21.00 \pm 1.53$ years; height $173.33 \pm 7.29 \mathrm{~cm}$; body weight $63.41 \pm 9.41$ $\mathrm{kg}$ ). Kinesiotape was carried out to the dominant ankle of the participants. Kinesiotape was applied supportively to peroneus longus, peroneus brevis, and tibiofibular ligament. All participants were taken to postural control measurements twice with Kinesiotape (KT) and without KT. Postural control was measured using the Biodex Balance System with eyes open (EO) and eyes closed (EC). Overall Stability Index (OSI), anterior-posterior sway (AP) and medio-lateral sway (ML) scores were used in the evaluation of postural control. Wilcoxon test was used to compare balance scores under EO condition, and the t-test was used for dependent groups to compare balance scores under EC condition.

Results In EO condition, no significant difference was found between OSI, AP, and ML scores of the taekwondo athletes with KT and without KT ( $p>0.05)$. In EC condition, no significant difference was found between $\mathrm{OSI}, \mathrm{AP}$, and ML scores of male taekwondo athletes with KT and without KT ( $p>0.05)$. It was found that Kinesiotape in EC condition decreased OSI and AP sway scores in female taekwondo athletes $(p<0.05)$.

Conclusions It was determined that ankle Kinesiotaping of taekwondo athletes did not change the postural balance in EO condition. In EC condition it did not change the postural sway of male taekwondo athletes, but it improved the postural control performances of female taekwondo athletes.

Keywords: balance, muscle performance, lower extremity, female, students.
\end{abstract}

\section{Introduction}

Taekwondo, which became a more popular sport after being an Olympic Sport in Sydney 2000 Olympics, is a traditional Korean martial art and martial sport [1, 2]. Taekwondo athletes should have a high level of aerobic capacity, anaerobic power, muscular strength, flexibility, and agility [3]. To achieve the best possible results in competitions, taekwondo athletes must have their own postural features in terms of balance and postural control as well as muscle symmetries [4]. Dynamic kicking techniques in Taekwondo require balance along with motoric features such as strength, speed, endurance, flexibility, and coordination [5]. Taekwondo athletes must provide dynamic stability on the support legs to perform fast and irregular movements with the foot they use while kicking [6]. Patti et al. [7] argue that balance in taekwondo control provides more effective stimulation for sensory-motor regulation compared to tennis. In Taekwondo, the lower extremities are the most affected body part of injuries [5] and $46 \%$ of the athletes reported that their lower extremity injuries recurred once more [8]. The most common injury in taekwondo athletes is ankle sprain [8].

\footnotetext{
(c) Yasemin Bayraktar, Nurtekin Erkmen, Yağmur Kocaoğlu,

Bayram Sönmez Ünüvar, 2021

doi:10.15561/20755279.2021.0602
}

When the centre of gravity stays within the limits of stability, two different strategies or combinations of strategies are used to move the centre of gravity while maintaining the previous position of the feet on the support surface [9]. Postural balance strategies consist of hip strategy and ankle strategy [10]. Compared to other sports branches, martial arts athletes use the ankle joints much more often. The success of these athletes in maintaining a balanced position predicts a good control of the lower extremity [11].

Postural control includes various physiological systems, including sensory units, muscle reflexes, and central nervous system [12]. Any disruption between components of this mechanism or interactions between components can disrupt postural balance [13]. Human upright posture is protected by the central nervous system through the integration of complex afferent and efferent control signals based on body orientation and movement information provided by vestibular, visual, and somatosensory systems [14].

Sports involvement requires high levels of control as voluntary movements, and external perturbations constantly threaten body stability in activities performed at high speeds [15]. Balance control, which allows the performance of activities ranging from maintaining static positions to complex dynamic activities, is vital for life 
[16]. Ankle, which is a tactile sense organ that keeps body weight in balance [17], plays an important role in posture and locomotion [18]. Peroneus muscles combined with the tibialis muscles support and stabilized the ankle joint [19]. Studies have shown that the peroneus longus muscle plays an important role in maintaining balance [20]. Ankle and foot injuries are common among athletes and physically active people. The most common residual discomfort, ankle sprain, is characterized by the instability of postural oscillation [21].

It is suggested that Kinesiotaping (KT) is an intervention that can improve postural control [22]. Studies have shown that Kinesiotape improves flexibility and increases postural balance as well as functional performance of individuals [23]. KT method can be used not only to prevent the progression of acute and chronic athletic injuries, but also to prevent the occurrence of musculoskeletal injuries and to improve performance [24]. Kinesiotape is completely different from existing sports medical tapes [25]. In addition to improving athletic performance, KT is a very useful method for preventing and treating a large number of musculoskeletal disorders [24]. It increases awareness in the ankle position by stimulating KT mechanoreceptors applied to the ankle. Also, the KT can increase the sense of joint position in the ankle [26].

KT provides a full range of motion for the muscles and joints applied by lifting the skin with different pulling forces to increase the gap between the skin and muscle [27]. The goal of KT is to change the underlying tissue for a long-term effect [28]. The general principle in KT is an activation of the affected area, removal of pathological changes that occur, and restoration of physiological functions. By applying KT, it may be possible to reduce pressure and stimulate certain receptors and nerve endings in a particular area to increase blood flow of damaged tissues and reduce edema [29, 24, 30].

KT reduces pain [31], increases efficiency in sports, accelerates lymph and venous transformation, and improves muscle performance [32]. It has also been seen that KT provides an increase in the bioelectric activity of the muscle [33]. This mechanism is thought to improve microcirculation between the dermis and epidermis. In addition to improving microcirculation, KT increases the activity of the lymphatic system and endogenous analgesic mechanisms; and by affecting muscle function it supports joint function. Furthermore, KT is reported to improve proprioception with normalization of muscle tone, correction of in appropriate position, stimulating effect on skin receptors [34]. However, in some studies, it was concluded that it did not develop proprioception [35, 36]. It has been suggested that by increasing the sensory input, it reduces delay in postural reflexes and improves dynamic balance by increasing postural stability [32]. Therefore, in this study, it was aimed to find out whether the KT applied to the ankle joint of healthy taekwondo athletes has an effect on postural control.

\section{Material and Methods}

\section{Participants}

The study included 24 healthy university students - taekwondo athletes (12 females, 12 males) who had not suffered from lower extremity injury in the last six months, and who did not have motor control problems, neurological disorders or vestibular disorders. The average age of the participants is $21.00 \pm 1.53$ years, their average height is $173.33 \pm 7.29 \mathrm{~cm}$ and their average body weight is $63.41 \pm 9.41 \mathrm{~kg}$. Participants who voluntarily agreed to participate in the research were informed about the research. The participants were asked to sign the voluntary consent form. This research, approved by the Ethics Committee of the [Blinded for review], was conducted in accordance with the Helsinki Declaration.

\section{Test procedure}

The participants were randomly taken to postural control measurements in two experimental conditions (with KT / without KT). All subjects participated in balance measurements with and without KT. The participants were randomly divided into two groups with equal numbers of males and females ( 6 females +6 males $=12$ for a group). To randomize the measurement sequence, a group was first applied with KT and then taken into postural control measurement. In the other group, postural control measurement was taken first and then KT was applied. Approximately 40-45 minutes after the application of KT, the participants were taken to postural control measurements.

\section{Postural control}

Biodex Balance System (BBS, Biodex Medical Systems Inc., Shirley, NY) was used to detect postural control (fig. 1).

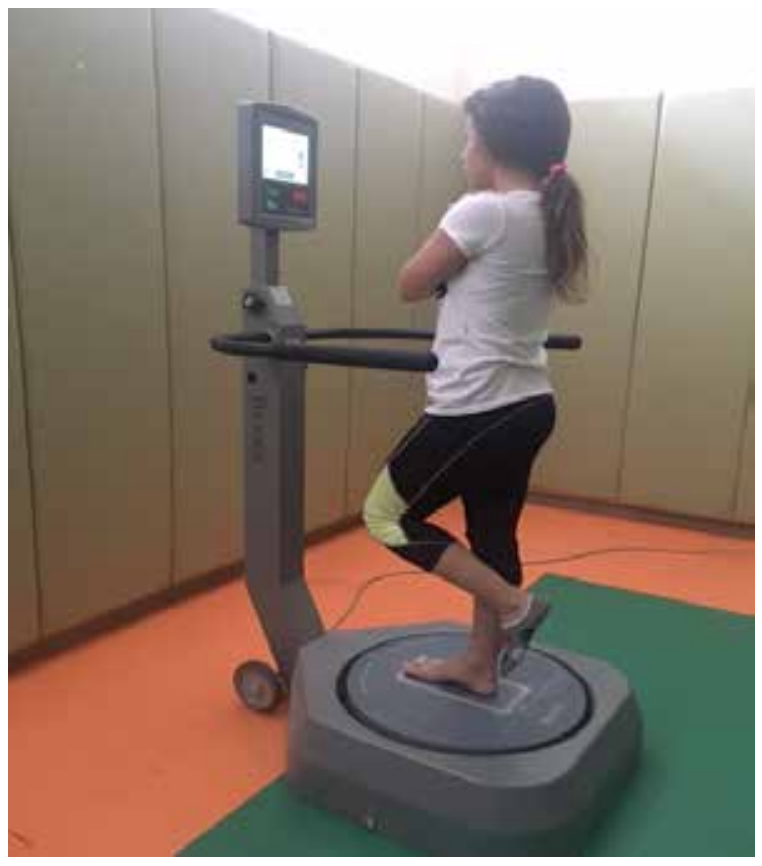

Figure 1. The measurement of postural balance.

This system is a tool that measures and records the ability of subjects to maintain their postures under 
dynamic stress. The BBS, which has a movable platform of $55 \mathrm{~cm}$ in diameter with a 360-degree movement width, has difficulty levels that can be adjusted from 12 to 1 . The high scores obtained from BBS express impaired balance performance [37, 38, 39]. Postural control measurements of participants were performed under two separate experimental conditions, eyes open (EO) and eyes closed (EC). Before the measurements, participants were allowed to experience sufficiently to get used to the measurement tool. Participants joined in measurements with their sportswear. Participants were asked the question "which foot do you use to hit a ball?" and the answer was accepted as the dominant leg, and postural control measurements were performed on the dominant leg in a single-leg stance. Participants were asked to stand on the moving platform of the BBS and stand with one footon the dominant foot-with their feet in the center of the platform and cross their arms with their hands touching their shoulders. The non-dominant leg was positioned not to touch the ground. In this experimental position, participants were asked to maintain a balanced posture on the measuring device, they were allowed to receive feedback from the screen of the measuring device, and the foot coordinates were recorded in the measuring device. These coordinates were accepted as reference points in all postural oscillation measurements.

Participants were taken to postural control measurement first in EO and then in EC condition. During this measurement, the difficulty level of the measuring tool was set to "Level 8" for the EO condition and "Static Level" for the EC condition. During the postural control test, the participants were asked to maintain the test positions first and then look at the screen of the measurement tool to provide a balanced posture. During both the EO and EC conditions, participants were asked to maintain their balanced positions for 20 seconds during the test. During postural control tests, the screen of the BBS was closed under EO condition and the subjects were asked to look at a marked spot for 20 seconds- which was in their eye alignment and on the wall about $1 \mathrm{~m}$ away; and in the EC condition, they were asked to close their eyes during the test. At the end of the test period, the test measurement tool was completed automatically and the subjects' 3 sway scores were recorded: Overall Stability Index (OSI, Overall Stability Index), Anterior-Posterior Index (AP), Medio-Lateral Index (ML). Participants who could not maintain their posture during the test were remeasured. A 2-minute rest was given between EO and EC measurements.

\section{Kinesiotaping (KT) application}

KT application was applied to the dominant ankle of the participants. KT application was performed by a certified physiotherapist in accordance with the technique. KT was applied supportively to peroneus longus, peroneus brevis, and tibiofibular ligament [40]. A $5 \mathrm{~cm}$ wide kinesio tapes (Kinesio ${ }^{\circledR}$ Tex) were used for taping (fig. 2).

Statistical Analysis

The normality distribution of the data was carried out by the Shapiro-Wilk test separately for all subjects, female and male subjects. Wilcoxon test was used to compare balance scores in EO condition that did not meet normal distribution conditions. To compare the balance scores under the normal distribution of EC conditions, a t-test was applied for dependent groups. IBM SPSS Statistics (Version 22 for Windows; IBM, Armonk, NY, USA) was used in the analysis of the data. Data results were evaluated at .05 significance level and $95 \%$ confidence interval.

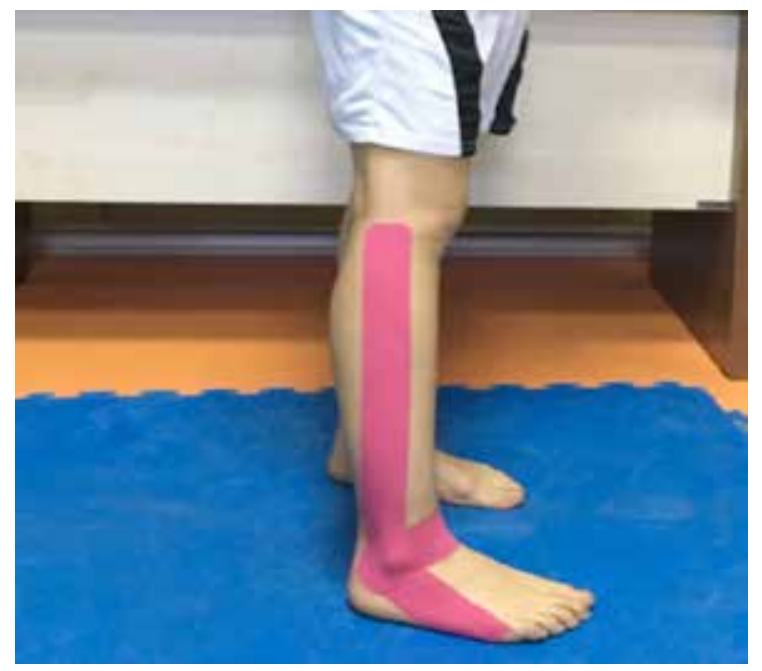

Figure 2. KT application.

\section{Results}

Descriptive statistics of 24 taekwondo athletes are given in Table 1. In Table 2, postural sway scores of taekwondo players with KT and without KT are presented.

It was seen that OSI scores in EO condition were not affected by the application of KT and in females $(\mathrm{Z}=$ $-0.315 ; \mathrm{p}=0.753)$, males $(Z=-1.227 ; \mathrm{p}=0.220)$ and all subjects $(Z=-0.635 ; p=0.525)$ no statistically significant difference was detected between measurements. Comparing AP sway scores under EO condition; it was observed that the application of KT for females $(\mathrm{Z}=$ $-1.341 ; p=0.180)$, males $(Z=-1.207 ; p=0.227)$ and all subjects $(Z=-0.290 ; p=0.772)$ did not have a significant effect and there was no statistically significant difference between repeated measurements. Similar results were determined in the scores obtained for ML sway under EO condition and it was determined that $\mathrm{KT}$ did not cause a statistically significant change in $\mathrm{ML}$ scores $(Z=-1.357$; $\mathrm{p}=0.175$ for females, $Z=-0.669 ; \mathrm{p}=0.503$ for males, $Z=$ $-1,441 ; p=0.150$ for all subjects).

The postural sway scores of taekwondo athletes measured with KT and without KT under the EC condition are presented in Table 3. Statistical analysis results indicated that OSI scores of female taekwondo athletes were affected by the KT application under EO condition, and OSI scores were significantly lower in the group without KT $(\mathrm{t}=-3.672 ; \mathrm{p}=0.004)$. As a result of the comparison of male taekwondo athletes and all taekwondo players, OSI scores were not significantly different between the measurements with and without 
Table 1. Subjects' physical characteristics.

\begin{tabular}{llc}
\hline Variables & Gender & Mean \pm SD \\
\hline \multirow{3}{*}{ Age (year) } & Female & $20.58 \pm 1.44$ \\
& Male & $21.42 \pm 1.56$ \\
Body Weight $(\mathbf{k g})$ & Total & $21.00 \pm 1.53$ \\
& Female & $57.72 \pm 5.33$ \\
& Male & $69.12 \pm 9.28$ \\
Height $(\mathbf{c m})$ & Total & $63.42 \pm 9.42$ \\
& Female & $168.92 \pm 5.86$ \\
& Male & $177.75 \pm 5.83$ \\
Sport Experience (year) & Total & $173.33 \pm 7.29$ \\
& Female & $6.71 \pm 1.98$ \\
& Male & $8.25 \pm 2.05$ \\
\hline
\end{tabular}

Table 2. Postural control scores with KT and without KT in EO condition (Mean \pm SD).

\begin{tabular}{lllll}
\hline Subjects & Groups & OSI & AP & ML \\
\hline Female & With KT & $1.64 \pm 0.49$ & $1.08 \pm 0.45$ & $1.02 \pm 0.38$ \\
& Without KT & $1.78 \pm 0.69$ & $1.38 \pm 0.64$ & $0.88 \pm 0.41$ \\
Male & With KT & $1.91 \pm 0.36$ & $1.18 \pm 0.32$ & $1.25 \pm 0.26$ \\
& Without KT & $1.85 \pm 0.86$ & $1.03 \pm 0.34$ & $1.28 \pm 0.90$ \\
Total & With KT & $1.78 \pm 0.44$ & $1.13 \pm 0.39$ & $1.13 \pm 0.34$ \\
& Without KT & $1.81 \pm 0.76$ & $1.20 \pm 0.53$ & $1.08 \pm 0.71$ \\
\hline
\end{tabular}

NOTE: OSI - Overall Stability Index; AP - Anterior-Posterior Index; ML - Medio-Lateral Index.

Table 3. Postural control scores with KT and without KT in EC condition (Mean \pm SD).

\begin{tabular}{lllll}
\hline Subjects & Groups & OSI & AP & ML \\
\hline Female & With KT & $2.26 \pm 0.55^{*}$ & $1.59 \pm 0.57^{*}$ & $1.23 \pm 0.34$ \\
& Without KT & $2.77 \pm 0.64$ & $2.23 \pm 0.62$ & $1.33 \pm 0.42$ \\
Male & With KT & $2.43 \pm 0.56$ & $1.64 \pm 0.52$ & $1.40 \pm 0.33$ \\
& Without KT & $2.35 \pm 0.57$ & $1.66 \pm 0.60$ & $1.33 \pm 0.28$ \\
Total & With KT & $2.34 \pm 0.55$ & $1.62 \pm 0.53^{*}$ & $1.32 \pm 0.34$ \\
& Without KT & $2.56 \pm 0.63$ & $1.95 \pm 0.66$ & $1.33 \pm 0.35$ \\
\hline
\end{tabular}

NOTE: OSI - Overall Stability Index; AP - Anterior-Posterior Index; ML - Medio-Lateral Index; * Significantly lower than without KT.

$\mathrm{KT}(\mathrm{t}=0.378$ and $\mathrm{p}=.713$ for males; $\mathrm{t}=-1.628$ and $\mathrm{p}=.117$ for all subjects). When the sway scores in the AP direction under the EC condition were examined; a statistically significant difference was found between the measurements with and without KT of female taekwondo athletes $(\mathrm{t}=-4.154 ; \mathrm{p}=0.02)$ and all subjects $(\mathrm{t}=-2.543$; $\mathrm{p}=0.018)$. There was no significant difference between AP sway scores of male taekwondo athletes $(t=-0.099$; $\mathrm{p}=.923)$. On the other hand, it was determined that there was no effect of the Kinesiotaping on ML direction sway scores in EC condition in females, males and all taekwondo athletes $(\mathrm{t}=-0.964 ; \mathrm{p}=.356$ for females, $\mathrm{t}=$ $0.643 ; \mathrm{p}=.533$ for males and $\mathrm{t}=-0.100 ; \mathrm{p}=.921$ for all subjects).

\section{Discussion}

In this study, the effect of the ankle KT of taekwondo athletes on postural balance in EO and EC conditions was examined. The effect of KT was determined by comparing the measurements of postural sway while the dominant ankle was in two experimental conditions with $\mathrm{KT}$ and without KT.

These results indicated that there was no change in postural control performances of both female and male taekwondo athletes in the EO condition with KT and without KT. In other words, it might be said that the KT does not have an effect on the balance abilities of taekwondo athletes in EO condition.

In EC condition, it was found some changes between balance scores in KT and without KT. It was seen that OSI and AP sway in female athletes were decreased by the application of KT in EC condition. However, no change was observed in male taekwondo athletes.

Many studies have investigated the effect of KT 
applied to the ankle on postural control [41-47]. In these studies, it is seen that various taping methods are used and the participants have different features. Also, the timing of measurement after KT application varies. As a result of these variations, it is difficult to agree on the influence of the KT.

Nakajima and Baldridge [42] reported that KT applied to the ankle in healthy males had no effect on dynamic postural balance, whereas in healthy females, a shortterm effect was not observed, and yet, postural balance improved 24 hours after the application of KT. Participants did not remove KT for 24 hours. Another study in healthy individuals reported that KT applied to the ankle did not improve proprioception [35]. Fayson et al. [45] also concluded that KT did not affect the stabilization time in healthy females. In elder healthy females, no change in postural balance was observed immediately after and after 48 hours of KT application [43]. Contrary to these results, Semple et al. [48], measured postural stability with and without KT measuring instrument (Biodex Balance System) used in this research and determined that KT reduced the OSI, AP, ML scores of the participants who were semi-professional rugby players, namely, increased their postural stability. There are other studies reporting that the KT develops postural balance in healthy individuals [46, 47, 49]. Vinken et al. [50], who examined the effect of KT in terms of performance of active dancers ( 2 males, 13 females) in terms of postural control and dance-specific routines, reached the conclusion that although the development of postural control was observed, the performance was limited in the performing of modern and classical dance routines. They emphasized that athletes could use KT for comfort and amenity, but the impact of functional performance still requires scientific evidence.

Although Hettle, Linton, Baker, and Donoghue [51], reported that the ankle KT application did not improve the reach of the Star Excursion Balance Test according to an investigation in athletes with chronic ankle instability, Alghamdi and Shawki [41], announced that it improved balance control in a similar sample. Unlike other studies, Jackson et al. [44], maintained the KT application for 48 hours and examined its effects for up to 72 hours. In the participants with chronic ankle instability, they demonstrated that balance improved 48 hours after the application of KT and this improvement continued 72 hours later.

It was observed that the KT applied to the ankle in female volleyball players did not affect the agility and jump performance, and also did not affect the balance scores using as measured by the Balance Error Scoring System, but this test performed in EC condition reduced the scores obtained on the foam surface, that is, fewer errors were detected on the foam surface [56]. Błaszczyk et al. [53], reported that females need higher muscle activity to maintain their body balance during a stable stance. In this study, as a result of the application of ankle KT, it was determined that there was no change in the postural control performances of male taekwondo athletes in the EC condition, while the postural control in the female taekwondo athletes improved in the EC condition. This result suggests that in conditions where the control of the balance is difficult and especially the visual system is obstructed, the KT applied to the ankle of female athletes might change the postural sway and show better postural performance due to the support it provides to the ankle. However, there is a need for new studies examining the effect of the KT in terms of the gender variable and sensory systems that affect balance control as to why this development does not occur in male athletes. KT application may have an effect that facilitates factors such as intermuscular, intramuscular coordination and even muscle co-contraction as well as sensory inputs [50]. Murray and Husk [27] have suggested that KT may cause an increase in joint position sensation as a result of the stimulation of cutaneous receptors, and reported that this may support healing and improve functional dynamic balance. There are studies reporting that 10 minutes after the application of the KT, it causes changes in blood flow [54] and has an effect on balance performance for up to 72 hours. However, it is controversial when the effects of postural control start or exactly what effect it has.

\section{Conclusions}

As a result, it is determined that the KT applied to the ankle of taekwondo athletes does not change the postural balance in EO condition, it does not change postural control in male taekwondo athletes in EC condition, but it improves the postural control performances in female taekwondo athletes. It can be said that the application of $\mathrm{KT}$ to the ankle does not limit the postural performance of taekwondo athletes and improves postural control under conditions where there is no visual input.

\section{Acknowledgements}

We thank to the participant students for their precious time and patience.

\section{Funding}

The paper is a part of Bayraktar's master thesis. It was supported financially by the Coordinator of Scientific Researches Projects (BAP) at Selcuk University (Project Number: 16202001).

\section{Conflict of interest}

The authors have no conflicts of interest that are directly relevant to the content of this study. 


\section{References}

1. Haddad M, Ouergui I, Hammami N, Chamari K. Physical training in Taekwondo: generic and specific training. In: Haddad M (Ed.). Performance optimization in taekwondo: from laboratory to field. Foster City, CA: OMICS Group eBooks; 2015. P. 85-93.

2. Kazemi M, Casella C, Perri G. 2004 Olympic Tae Kwon Do athlete profile. J Can Chiropr Assoc, 2009;53(2):144-152.

3. Lystad RP, Graham PL, Poulos RG. Epidemiology of training injuries in amateur taekwondo athletes: a retrospective cohort study. Biol Sport, 2015;32(3):213-410. https://doi.org/10.5604/20831862.1150303

4. Barcellona M, Giustino V, Messina G, Battaglia G, Fischetti F, Palma A, et al. Effects of a specific training protocol on posturographic parameters of a taekwondo elite athlete and implications on injury prevention: A case study. Acta Medica Mediterranea, 2018;34:1533-1538. https://doi.org/10.19193/0393-6384_2018_3s_236

5. Lystad RP, Pollard, H Graham PL. Epidemiology of injuries in competition taekwondo: a meta-analysis of observational studies. J Sci Med Sport, 2009;12:614-621. https://doi.org/10.1016/j.jsams.2008.09.013

6. Son M, Youm C, Woo J, Lee M, Kim Y, Kim J. Postural stability for taekwondo athletes with repetitive ankle sprains during a single-leg stance. J Phys Ther Sci, 2018;30(3):405-410. https://doi.org/10.1589/jpts.30.405

7. Patti A, Messina G, Palma R, Barcellona M, Brusa $\mathrm{J}$, Iovane A, et al. Comparison of posturographic parameters between young taekwondo and tennis athletes. J Phys Ther Sci, 2018;30(8), 1052-1055. https://doi.org/10.1589/jpts.30.1052

8. Schlüter-Brust K, Leistenschneider P, Dargel J, Springorum HP, Eysel P, Michael JW. Acute injuries in Taekwondo. Int $J$ Sports Med, 2011;32:629-634. https://doi.org/10.1055/s-0031-1275302

9. Nashner LM. Practical biomechanics and physiology of balance. In: Jacobson GP, Newman CW, Kartush JM (Eds.). Handbook of Balance Function Testing. San Diego, USA: Singular Publishing Group, Inc.; 1997. P.100-110.

10.Creath R, Kiemel T, Horak F, Peterka R, Jeka J. A unified view of quiet and perturbed stance: simultaneous coexisting excitable modes. Neurosci Lett, 2005;377(2):75-80. https://doi.org/10.1016/j.neulet.2004.11.071

11.Gorgy OVJ, Coyle T. How does practise of internal Chinese martial arts influence postural reaction control? J Sports Sci, 2008;26(6), 629-642. https://doi.org/10.1080/02640410701670401

12. Winter DA. Human balance and posture control during standing and walking. Gait \& Posture, 1995;3(4):193-214. https://doi.org/10.1016/0966-6362(96)82849-9

13.Horak FB. Postural orientation and equilibrium: what do we need to know about neural control of balance to prevent falls? Age and Ageing, 2006;35:ii7-11. https://doi.org/10.1093/ageing/afl077

14.Peterka RJ. Senserimotor integration in human postural control. J Neurophysiol, 2002;88(3):1097-118. https://doi.org/10.1152/jn.2002.88.3.1097

15.Bennell KL, Goldie PA. The differential effects of external ankle support on postural control.JOSPT, 1994;20(6):287-95. https://doi.org/10.2519/jospt.1994.20.6.287

16.Hassan BS, Mockett S, Doherty M. Static postural sway, proprioception, and maximal voluntary quadriceps contraction in patients with knee osteoarthritis and normal control subjects. Ann Rheum Dis, 2001;60:612-618. https://doi.org/10.1136/ard.60.6.612
17.Bal A, Gürçay E, Aydoğ E, Ekşioğlu E, Çakcı A. Assessment of foot-ankle involvement and deformities in patients with psoriatic arthritis. Turkiye Klinikleri J Med Sci, 2008;28, 672-76.

18.Gage JR, Deluca PA, Renshaw TS. Gait analysis: principles and applications. J Bone Jt Surg, 1995;77-A(10):1607-1623. https://doi.org/10.2106/00004623-199510000-00017

19.DeRidderR, WillemsT, VanrenterghemJ,RoosenP.Influence of balance surface on ankle stabilizing muscle activity in subjects with chronic ankle instability. JRehabil Med, 2015;47:632-38. https://doi.org/10.2340/16501977-1970

20.Louwerens JW, van Linge B, de Klerk LW, Mulder PG, Snijders CJ. Peroneus longus and tibialis anterior muscle activity in the stance phase. A quantified electromyographic study of 10 controls and 25 patients with chronic ankle instability. Acta Orthop Scand, 1995;66(6):517-523. . https://doi.org/10.3109/17453679509002306

21.Denegar CR, Miller SJ. Can chronic ankle instability be prevented? Rethinking management of lateral ankle sprains. $J$ Athl Train, 2002;37(4):430-435.

22. Yoshida A, Kahanov L. The effect of Kinesio taping on lower trunk range of motions. Research in Sports Medicine, 2007;15:103-11. https://doi.org/10.1080/15438620701405206

23.Jaraczewska E, Long C. Kinesio tape in stroke improving functional use of the upper extremity in hemiplegia. Top Stroke Rehabil, 2006;13(3):31-42. https://doi.org/10.1310/33KA-XYE3-QWJB-WGT6

24.Pysny L, Jana P, Petru D. Kinesio taping use in prevention of sports injuries during teaching of physical education and sport. Procedia-SocialandBehavioral Sciences, 2015;186:618-623. https://doi.org/10.1016/j.sbspro.2015.04.039

25.Gramatikova M, Nikolova E, Mitova S. Nature, application and effect of kinesio taping. Activities in Physical Education and Sport, 2014;4(2):115-119.

26. Simoneau GG, Degner RM, Kramper CA, Kittleson KH. Changes in ankle joint proprioception resulting from strips of athletic tape applied over the skin. J Athl Train, 1997;32(2):141-147.

27. Murray H, Husk L. Effect of Kinesio ${ }^{\mathrm{TM}}$ taping on proprioception in the ankle. J Orthop Sports Phys Ther, 2001;31A-37.

28.An HM, Miller C, McElveen M, Lynch J. The effect of Kinesio Tape ${ }^{\circledR}$ on lower extremity functional movement screen $^{\mathrm{TM}}$ scores. International Journal of Exercise Science, 2012;5(3):196-204.

29.Briem K, Eythörsdöttır H, Magnüsdöttır RG, Palmarsson R, Runarsdöttır T, Sveinsson T. Effects of Kinesio tape compared with nonelastic sports tape and the untaped ankle during a sudden inversion perturbation in male athletes. J Orthop Sports Phys Ther, 2011;41(5):328-621. https://doi.org/10.2519/jospt.2011.3501

30.Castro-Sanchez AM, Lara-Palomo LC, Mataran-Penarrocha GA, Fernandez-Sanchez M, Sanchez-Labraca N, ArroyoMorales M. Kinesio taping reduce disability and pain slightly in chronic non-specific low back pain: a randomized trial. Journal of Physiotherapy, 2013;58(2):89-95. https://doi.org/10.1016/S1836-9553(12)70088-7

31.Chen PL, Hong WH, Lin CH, Chen WC. Biomechanics effects of kinesiotaping forpersons with patellofemoral painsyndrome during stair climbing. IFMBE Proceedings, 2008;21:395-97. https://doi.org/10.1007/978-3-540-69139-6_100

32.Riemann BL, Myers JB, Lephart SM. Sensorimotor system measurement techniques. J Athl Train, 2002;37(1);85-89.

33.Slupik A, Dwornik M, Bialoszewski D, Zych E. Effect of 
Kinesio taping on bioelectrical activity of vastus medialis muscle. Preliminary report. Ortopedia Traumatologia Rehabilitacja, 2007;9(6):644-651.

34.Breitenbach S. Kinesio-taping eine neue, revolutionare technik [Kinesio taping- a new, revolutionary technique!]. Physikalische Therapie, 2004;1:16-20.

35.Halseth T, McChesney JW, DeBeliso M, Vaughn R, Lien J. The effects of Kinesio taping on proprioception at the ankle. J Sport Sci Med, 2004;3:1-7.

36.Chang WD, Chen FC, Lee CL, Lin HY, Lai PT. Effects of kinesio taping versus mcconnell taping for patellofemoral pain syndrome: A systematic review and meta- analysis. Evid Based Complement Alternat Med, 2015;1-11. https://doi.org/10.1155/2015/471208

37.Cachupe WJC, Shifflett B, Kahanov L, Wughalter EH. Reliability of Biodex Balance System measures. Meas Phys Educ Exerc Sci, 2001;5:97-108. https://doi.org/10.1207/S15327841MPEE0502_3

38. Arnold BL, Schmitz RJ. Examination of balance measures produced by the Biodex Stability System. J Athl Train, 1998;33(4):323-27.

39.Hinman MR. Factors affecting reliability of the Biodex Balance System; a summary of four studies. $J$ Sports Rehabil, 2009;240-252. https://doi.org/10.1123/jsr.9.3.240

40.Bleakley CM, McDonough SM, Macauley DC. Cryotherapy for acute ankle sprains: a randomised controlled study of two different icing protocols. Br J Sports Med, 2006;40:700-705. https://doi.org/10.1136/bjsm.2006.025932

41.Alghamdi A, Shawki M. The effect of Kinesio taping on balance control and functional performance in athletes with chronic ankle instability. MOJ Orthop Rheumatol, 2018;10(2):114-120. https://doi.org/10.15406/mojor.2018.10.00398

42.Nakajima MA, Baldridge C. The effect of Kinesio tape on vertical jump and dynamic postural control. IJSPT, 2013;8(4):393.

43.Cabreira TS, Coelho KHV, Quemelo PRV. Kinesio Taping effect on postural balance in the elderly. Fisioter Pesq, 2014;21(4):333-338. https://doi.org/10.590/1809-2950/12320821042014

44.Jackson K, Simon JE, Docherty CL. Extended use of Kinesiology tape and balance in participants with chronic ankle instability. $J$ Athl Train, 2016;51(1):16-21. https://doi.org/10.4085/1062-6050-51.2.03
45.Fayson SD, Needle AR, Kaminski TW. The effects of ankle kinesio ${ }^{\circledR}$ taping on ankle stiffness and dynamic balance. Research in Sports Medicine: An International Journal, 2013; 21(3): 204-216. https://doi.org/10.1080/15438627.2013.792083

46.Şahan AK, Ünver F. The acute effects of ankle Kinesio taping on balance in healthy individuals. Journal of Exercise Therapy and Rehabilitation, 2017;(Sup 4):S10. https://doi.org/10.47447/tjsm.0489

47.Gök H, Örücü Atar M, Ateş C, Sonel Tur B. Does Kinesiotaping affect standing balance in healthy individuals? A pilot, double-blind, randomized-controlled study. Turk J Phys Med Rehabil, 2019;65(4):327-334. https://doi.org/10.5606/tftrd.2019.3788

48.Semple S, Esterhuysen C, Grace J. The effects of Kinesio ankle taping on postural stability in semiprofessionel rugby union players. $J$ Phys Ther Sci, 2012;24:1239-1242. https://doi.org/10.1589/jpts.24.1239

49.Soysal Tomruk M, Tomruk M, Alkan E, Gelecek N. The effect of ankle Kinesio tape application on limits of stability and flexibility in healthy young adults. Journal of Exercise Therapy and Rehabilitation, 2017;Sup(4):S02.

50.Vinken PM, Hennig L, Heinen T. Short- term effects of elastic taping on dancer's postural control performance. Central European Journal of Sport Sciences and Medicine, 2014;8(4):61-62.

51.Hettle D, Linton L, Baker JS, Donoghue O. The effect of kinesiotaping on functional performance in chronic ankle instability- preliminary study. Clin Res Foot Ankle, 2013;1(1):1-5. https://doi.org/10.4172/2329-910X.1000105

52.Karkın T, Erkmen N, Bayraktar Y, Kocaoğlu Y, Ünüvar BS. Effects of kinesio taping applied to the ankle on agility, power and postural control in female volleyball players. Nat J Kinesiol, 2020;1(2):35-44.

53.Błaszczyk JW, Beck M, Sadowska D. Assessment of postural stability in young healthy subjects based on directional features of posturographic data: vision and gender effects. Acta Neurobiol Exp, 2014;74:433-442.

54.Kase K, Hashimoto T. Changes in the volume of the peripheral blood flow by using Kinesio Taping ${ }^{\circledR}$. [Internet]. 1998 [cited 2021 August 15]. Available from: http://www. sportmedicine.ru/articles/changes in the volume of the peripheral_blood_flowby_usin_kinesio_taping.htm 


\section{Information about the authors:}

Yasemin Bayraktar; https://orcid.org/0000-0002-3417-0353; yaseminagar1@gmail.com; Sports Science Faculty, Selçuk University; Konya, Turkey.

Nurtekin Erkmen; https://orcid.org/0000-0002-5220-887X; nerkmen@gmail.com; Sports Science Faculty, Selçuk University; Konya, Turkey.

Yağmur Kocaoğlu; (Corresponding Author); https://orcid.org/0000-0001-6811-4205; ygmrkocaoglu@hotmail.com; Sports Science Faculty, Selçuk University; Konya, Turkey.

Bayram Sönmez Ünüvar; https://orcid.org/0000-0003-2095-3645; bayram.sonmez.unuvar@karatay.edu.tr; Vocational School of Health Services, Karatay University; Konya, Turkey.

\section{Cite this article as:}

Bayraktar Y, Erkmen N, Kocaoğlu Y, Ünüvar BS. The effects of ankle Kinesiotaping on postural control in healthy taekwondo athletes. Physical Education of Students, 2021;25(6):345-352.

https://doi.org/10.15561/20755279.2021.0602

This is an Open Access article distributed under the terms of the Creative Commons Attribution License, which permits unrestricted use, distribution, and reproduction in any medium, provided the original work is properly cited http://creativecommons.org/licenses/by/4.0/deed.en

Received: 15.09 .2021

Accepted: 18.10.2021; Published: 30.12.2021 